\title{
ARTICE Critical reflection: a sound foundation for learning and practice in psychiatry
}

\author{
Stavros Bekas
}

\begin{abstract}
Stavros Bekas is a Fellow in Medical Education, Leadership and Management at the London Deanery School of Psychiatry, and has been a psychiatrist since 2002 in various training and career posts in London. He has studied and conducted researched at King's College London's Institute of Psychiatry and the University of London's Institute of Education, with special interests in mental health services, leadership, supervision and reflective practice. Correspondence Dr Stavros Bekas, London Deanery School of Psychiatry, Stewart House, 32 Russell Square, London WC1B 5DN UK. Email: stavros.bekas@nhs.net.
\end{abstract}

\begin{abstract}
SUMMARY
A genuinely critical and reflective approach to psychiatry can potentiate learning, improve practice and promote personal development. To support this assertion, I attempt to link theory and practice. Following a brief overview of the seminal ideas that permeate the literature on critical thinking, I present three perspectives of reflective practice - those of the psychiatric trainee, the teacher and the practitioner - through examples of reflective exploration of personal experience, under the light of relevant evidence. I conclude with a critique on the limitations of reflective psychiatry.

DECLARATION OF INTEREST

None.
\end{abstract}

Doctors are expected to possess not only technical skills and knowledge; psychosocial understanding, cultural awareness, ethics and communication are today essential elements of clinical training and medical professionalism (General Medical Council 2006, 2009). Psychiatry in particular transcends biological and humanistic sciences, and effective care of mental disorder requires a holistic approach. Our modern world is characterised by multiple discourses and epistemologies, rapid creation and flow of information, internationalism and multiculturalism (Lyotard 1984). In this context, biomedicine is an inadequate paradigm for mental healthcare and invoking medical authority is not sufficient in the face of difficult questions. As a result, psychiatry requires learning and models of practice that reach beyond mere technical knowledge and create open-minded practitioners and lifelong learners. Critical reflection could potentially be such a model.

\section{Reflection as learning}

Reflection is inherent in learning and professional life, and is employed whenever we actively process or restructure an experience on the basis of prior knowledge and future objectives (Korthagen
2001). Critical reflection (known also as reflectivity, criticality and critical thinking) could be defined as:

'all the emotional and intellectual activity through which we critically assess the content, process or premise of our efforts to interpret and give meaning to an experience' (Mezirow 1981).

Reflective practice implies an active, iterative process that brings a conscious change in a cognitive, affective or psychomotor state, reaching new understandings (Boud 1985). As such, reflective practice is in itself a model of learning.

\section{Reflective activity and experiential learning}

Ideas of 'thinking about one's thoughts' and 'questioning one's knowledge' existed in ancient philosophy, as in the traditions of Socrates and Confucius. The title of modern father of reflection in learning belongs to Dewey. He argued that the learner develops higher-order understanding and practice through 'reflective activity'. He saw this as a conscious, purposeful activity of willing and open-minded intellects that attempt to match new experience with pre-existing ideas for interpretation and further action (Dewey 1933). Dewey contrasted reflection with lower-order processes, continuous 'trial and error' loops or capricious and instinctive 'impulses' based on tacit motives and assumptions that cannot be made explicit, justified or controlled. Students and practitioners may be seduced by the familiarity and effortlessness of habitual premises, rules of thumb or assumptions, as long as these remain effective, at least superficially. Reflective thinking instead can be unsettling, as it often arises when we experience mismatch between our expectations and results.

Dewey described reflective thinking as a number of distinct mental states, though not always in a strict succession:

- perplexity, caused by the failure of a habitual action or conjecture to produce the anticipated result

- intellectualisation, which is initiated by a critical survey of the situation and produces an understanding 
- the creation of alternative hypotheses or solutions; hypothesis testing starts new reflection.

Recognising the influence of Dewey, Kolb (1984) proposed a similar model of cyclical experiential learning where concrete experience is observed and described, reflection leads to abstraction and decontextualisation, and the product theory can be tested in future encounters with concrete experience (Fig. 1).

\section{Reflection as transformation}

Mezirow (1997) assimilated many of these ideas in his model of 'transformative learning', at the core of which is reflective thinking. He believed that reflection permits awareness and interpretation of experiences, constructs and actions, enabling us to produce 'meaning schemes' (Box 1), but additionally he argued in favour of a critical consideration of our frames of reference and internal processes. This meta-reflection is necessary for 'perspective transformation', i.e. the realisation of the complex psychosocial factors that determine our perspective of the world and a point of genuine change and liberation (Mezirow 1981).

Habermas (1971) described how learning may focus on 'technical analytical' aspects (e.g. biomedicine) or on 'meaning and interpretation' using communication and language (e.g. psychology and sociology) and that reflection is particularly conducive to the latter. He also posited that understanding ourselves and the social environment in which we think and act is the only knowledge that leads to true emancipation. The reflective thinker can identify ideologies, rules, habits and emotions that determine the frames of action and challenge them accordingly. Freire (1971) also believed in the liberating power of an education that teaches learners to critically reflect on their situational restrictions and become conscious of their sociopolitical existence.

\section{The early learner's perspective}

Looking back to my early years as a trainee, I realise how little I was equipped for the challenges of psychiatry. Entry criteria to medical school ensure that students excel in the natural sciences. Classic curricula emphasise biomedicine - social, psychological and communicative aspects are not studied as extensively. In addition, there is ongoing tension between the breadth of syllabus and depth of knowledge that does not allow full coverage and leads to over-reliance on strategic learning, lists of facts, rules or 'typical' cases. Specialist courses are not dissimilar. The psychiatry curriculum aspires to wide coverage of all biopsychosocial facets of

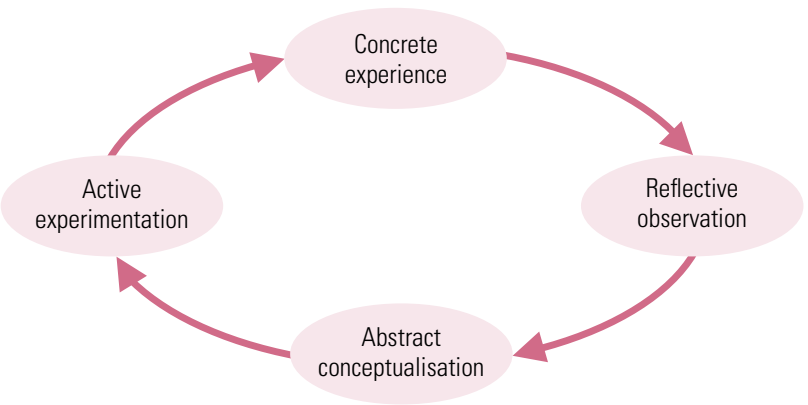

FIG 1

Kolb's theory of experiential learning (after Kolb 1984).

mental health (Royal College of Psychiatrists 2010a), but on-the-job training prioritises the identification of symptoms and their treatment, the teachers acting as 'gatekeepers' of knowledge (Jones 2005). However, in psychiatry, many cases seem not to fit snugly to textbook descriptions. Uncertainty is the rule, and the individual and their context are as important as the syndrome in planning care, making a purist medical model unsuitable.

In retrospect, my journey through psychiatry training was an idiosyncratic reflective process where difficulty in finding answers led to critical appraisal and search for alternative meanings or theories. As Dewey (1933) wrote, learners tend to stick to the available and the familiar until these fail to bring results. My habitual course of action was to find knowledgeable senior colleagues who could 'transmit' facts. Usually a one-off, quick enquiry was not sufficient to prepare for a dissimilar case; methodical reflection was a more efficient way of intellectualising the problems and finding solutions without relying on ready answers. 'Facts' or 'rules' could only partly answer the questions, and new methods of creating meaning and understanding increasingly became more important.

\section{Barriers to trainee reflective practice}

Reflection is a natural property of the adult thinker when confronted by challenge. Given the thinking

BoX 1 Meaning schemes

'Meaning schemes' are the little tacit rules and filters we use to interpret new information. They are determined by our accumulated knowledge, values and beliefs. Mezirow (1997) believed that, put together, meaning schemes create our overall perspective of the world. He also argued that many of our fundamental meaning schemes are developed in early life and can influence later interpretations of experience. That is why he considered critical reflection on well-ingrained meaning schemes as the prime target of 'transformative learning'. 
†For a discussion of portfolio-based learning and an example of a structured reflective questioning template, see pp. 329-336, this issue. Ed. space, self-consciousness can question the efficacy, validity and value of ideas and actions (Mezirow 1981). However, in many courses reflective learning seems opportunistic and discretionary and can be disrupted or even prevented within established apprenticeship models by the limited 'legitimate participation' of new entrants (Lave 1991). Induction into the community of psychiatric practice may restrict the depth and pace of participation. Medicine has a highly hierarchical structure and new learners often face a maze of rule-bound social associations with seniors and other disciplines. This gives the impression of hierarchy within reflective practice: higher-order reflections become permissible as status increases. Lack of central participation may discourage a natural tendency for reflective thinking; instead, rules and chunks of knowledge from the 'oldtimers' are promoted as the initiating steps to acquire legitimacy in this community. Reflective experience is often supplanted by examinations and workplace-based assessments of measurable competence, and trainees are often preoccupied with what is expected of them (Boud 1985) rather than with their learning needs.

\section{Integrating reflection into training and the workplace}

If all of this is necessary for reasons of accountability or safety, vicarious experiences could be used for reflection (Box 2). When shadowing consultants, trainees' learning can be enhanced greatly if the consultants demonstrate critical reflection in decision-making, thus not only teaching through example, but also expanding the observations on which learners can base their own critical reflection. This requires an atmosphere of openness, equality and freedom of speech, which is not always available (Grant 2003). A receptive community of practice, where newcomers are treated with respect and are offered early concrete experience, would be a fertile ground for reflective learning.

Psychiatry is in a privileged position because of its protected time for supervision, but the ability of supervisors to assist reflective learning varies (Kilminster 2000; Grant 2003; Launer 2006). The most positive experience of supervision I had involved a dialectic analysis on events and cases. As Launer (2006) proposes, storytelling, thinking aloud and questioning can reveal and challenge tacit theories, assumptions and attitudes in dealing with psychiatric cases. Bringing these to light permits scrutiny, reconstruction and testing in future action. Engeström (2001) also suggested 'investigative' learning cycles, where cognitive
B0X 2 Integrating reflection into training and the workplace

- Supervision using cases and narratives

- Observing reflection when shadowing seniors

- Reflective-questioning templates, diaries, notes and portfolio records

- Reflective writing

- Multisource feedback and workplace-based assessments

- Groups for problem-based learning, case discussion, action learning and peer support

- Balint groups and psychodynamic supervision

- Mentoring and coaching

conflict created by the failure of usual approaches to produce meaning or solution prompts reflection. 'Problems' posed by supervisors need to be realistic, multifactorial situations (e.g. ethics and care planning challenges) that can be intellectualised and analysed reflectively, rather than decontextualised questions of fact.

It has been widely argued that reflective aids (e.g. templates prompting reflective questioning; critical incident reports; personal diaries; reflective writing) can contribute to transformative learning, particularly of values and attitudes (Gibbs 1988; Boud 1990; Rolfe 2001; Rodgers 2002; Atkins 2003; Branch 2005), and the Royal College of Psychiatrists (2010b) recommends that they be included in appraisal portfolios. ${ }^{\dagger}$ Social components of reflective learning are equally important (Boud 1985): peer-group meetings for problem-based learning or case discussion can accelerate participation and create microcommunities of reflective practice using, for example, action learning (Box 3) (Dilworth 1998). Finally, psychotherapy can play a role in the development of reflective psychiatrists, for

\section{B0X 3 Action learning}

Action learning is an accelerated, action-focused learning method in which a group of practitioners meet regularly to help each other to reflect on and learn from their experience. Theorists maintain that it derives from the combination of instruction or 'programmed knowledge' (P) and reflection or 'questioning insight' (0). Action learning is achieved through small groups in which members reflect on real work problems characterised by the absence of 'right' answers. Reflection is facilitated through a semi-structured dialogue and mutual support and keeping track of progress between meetings. 
example through Balint groups, group therapy and psychodynamic supervision (Grant 1993; Hopkins 1994).

\section{The teacher's perspective}

Critical reflection can facilitate learning when teachers evoke it through their style of teaching or use it to analyse their experiences as teachers. Dewey (1933) highlighted the important role of teachers in reflection. He argued that anything teachers do, one way or another, elicits a response in learners; overcoming the preoccupation with what 'facts' to teach and how to present them, teachers should focus their efforts on creating an environment and opportunities conducive to student reflection and discovery. This is the foundation of the teacher as 'facilitator of knowledge construction', the Socratic method eloquently reformulated by Jones (2005) as the 'midwife' or 'fellow-traveller' approach. Such an environment was described by Schön (1987) as the 'reflective practicum' and by Brookfield (1987) as the 'critically reflective classroom': a laboratory of thinking where learners can use concrete or intellectual experience, under the facilitation of the teacher, to practise reflection in safe conditions permissive of critique and transformation. It becomes particularly pertinent in psychiatry, where some of our knowledge base is not strictly empirical, and practice often eschews 'objective' scientific method. For example, the concept of mental disorder is in many respects different from 'biological' disease; the essential feature is a cluster of signs and symptoms, only approachable through dialogue, empathy and reflection - more artistry than science.

\section{Activating transformative learning}

Reflecting on this complexity, I developed a series of tutorials on diagnosis for students and trainees. These tutorials aim to activate 'transformative learning' based on discussions about psychiatric knowledge and practice and the multifaceted influence of society and culture. This can happen by asking questions fraught with value judgements and creating conditions for critical reflection (Box 4). When teaching, I try to act like a 'coach' (Schön 1987) who avoids giving ready answers. Working on the principle that adult students possess the abilities to reflect on such issues, the teacher is there to provide the right mixture of questioning, challenge and support and to create realistic situations in which these questions can be investigated, for example when working with patients and their care team, or during paper exercises using vignettes drawn from practice.
BOX 4 Reflective practicum questioning: psychiatric diagnosis

- What is the difference between 'psychiatric' and 'physical' diagnosing?

-What constitutes mental disorder?

-Where is the threshold for intervention?

-What is the purpose of treatment?

-What are disability and recovery?

- What are the societal attributes assigned to psychiatrist and patient?

Such a setting is especially useful in the analysis of narratives, emotions, values and attitudes, and can challenge stigma.

The reflective tutor should also observe and reflect on the direction of the learning activity by keeping track of events. In my tutorials I try to monitor nuances of the dialogue, non-verbal communication and participation, often inviting criticism and opposing opinions, or discovering gaps in my own knowledge. The literature refers to such challenges in teaching as 'critical incidents' (Box 5). These events may seem trivial, but they are useful material for reflection. Tripp (1993) suggested that any incident or pattern in events can be rendered 'critical' when translated into a concise narrative and used as material for structured reflective analysis and modification of action. Such events tend to have in common some discomfort or disequilibrium (Cunningham 2008).

BOX 5 The quiet student: a tutor's analysis of a critical incident

- Incident: a particular student always stays quiet during interactive tutorials.

- Reflection and hypothesis: the student may feel alienated by my teaching methods, conflict with their habits, anxiety to 'get it right' or 'pass', aversion to self-disclosure.

- Hypothesis-testing and action: invite the students' opinions and confidential feedback, test modifications of the tutorial, e.g. avoid summative assessment, encourage the students to discuss the topic among themselves, direct questions to the quiet student.

- Results and meta-reflection: attempts to involve the student seem to fail, and I am at risk of blaming the student and patronising or oppressive teaching; position my teaching in its wider context: a long curriculum and sociocultural influences; temper my ambitions of allencompassing transformation and my belief in its value. 
TABLE 1 Two sides of professional practice

\begin{tabular}{|c|c|}
\hline The technical rational paradigm & The reflective paradigm \\
\hline Objective - 'science' & Subjective - 'artistry' \\
\hline $\begin{array}{l}\text { Nomothetic (generalised rules, guidance, } \\
\text { policies) }\end{array}$ & $\begin{array}{l}\text { Idiographic (life experience and individual } \\
\text { meaning) }\end{array}$ \\
\hline Favours scientific rigour & Favours clinical and individual relevance \\
\hline $\begin{array}{l}\text { Intolerant of uncertainty and ignorance, } \\
\text { often invoking professional authority }\end{array}$ & $\begin{array}{l}\text { Accepting of uncertainty and ignorance, } \\
\text { less imposing and authoritative }\end{array}$ \\
\hline $\begin{array}{l}\text { Unilateral inferences from observations } \\
\text { compared against unique, prior reference }\end{array}$ & $\begin{array}{l}\text { Iterative hypotheses with multiple references } \\
\text { (e.g. patients, carers, colleagues) }\end{array}$ \\
\hline $\begin{array}{l}\text { Applies prior developed theory after } \\
\text { reduction of the problem to its constituents }\end{array}$ & $\begin{array}{l}\text { Develops novel theory on the spot, reflecting } \\
\text { on the situation 'gestalt' }\end{array}$ \\
\hline $\begin{array}{l}\text { Claims that 'espoused' theory and } \\
\text { 'theory in use' are the same, no 'blind spots' }\end{array}$ & $\begin{array}{l}\text { Aims to reveal that 'theory in use' } \\
\text { often diverges from 'espoused' theory }\end{array}$ \\
\hline
\end{tabular}

Adapted from Schön 1983. the traditional 'technical rational' paradigm for professional practice. His work was a product of the gradual realisation in the 1970s that the positivism and technology which had established the modern professions could not account for all human experience. Schön's 'reflective practitioner' was also a response to those 'experts' who shield their practice with an air of mystification, aiming to preserve status and autonomy in the face of challenging criticism, and to achieve the 'cooperation' of their clients. He also attempted to address the gulf that separated nomothetic academic research and idiographic frontline practice (Table 1).

Real-life professional practice is characterised by artistry, often based on tacit knowledge, at the centre of which is a reflective loop that does not conform to the methods of academia. Nevertheless, this does not automatically achieve higher levels of criticality. Thus, in instrumental, problem-solving reflection the goal and the frame of reference are taken for granted and the effort is to reformulate theory and technique in order to reach the desired outcome. In contrast, complete learning involves meta-reflections that challenge the goal, motivation and explanatory model itself (Argyris 1996), indicating the importance not only of finding the 'right answers' but also of asking the 'right questions'.

\section{The 'theory in use' model}

In my experience, such an approach is particularly useful in setting psychiatry in its wider context and in acknowledging complexity and subjectivity, especially when communicating with patients and colleagues who have not been trained in the same way. When I formulate a case in order to inform care planning, I try to bear in mind that psychiatry has a long history of vicissitudes between conflicting paradigms, none of which can fully address the complexity of mental states. The discovery of drugs that were far superior to psychoanalysis in the treatment of psychosis is just the latest episode and founded psychiatry firmly in the technical rationality of bioscience - albeit, in common with most of medicine, technical rationality remains a partial explanatory model. As described earlier, diagnosis highlights not only the importance of professional skill but also its contextual frames of reference. In clinical practice, a tacit pattern recognition developed with experience gives rise to a hypothesis that is proved, rather than disproved (Popper 1968). Similarly, although basing treatment decisions on best available evidence is advocated, 'knowledge' produced by research is limited by generalisability/ 
clinical relevance in inverted relation to rigour and objectivity. Although statistics might predict events in populations, they cannot reliably forecast individual cases because of the existence of the recognisable syndrome with virtually unlimited individual factors (Sackett 1991). As a result, clinicians often draw evidence from the collection of 'cases' they have seen throughout their careers, which has little scientific robustness, but high validity for the individual.

This is an example of 'theory in use' (Argyris 1996), an explanatory and action model that, although frequently employed, is rarely made explicit. In the extreme, such tacit theories, if they are applied uncritically as all-explaining, can restrict our perspective of patient suffering. In a psychiatrist, this can happen under the guise of a striving to be rational, unemotional and objective, while defining problems and desired outcomes unilaterally, usually in terms of symptoms and their control. Diagnosis and treatment plan may be based on inferences, and value judgements on states of mind, functioning and problems that are not thoroughly tested for their validity in a dialogue with the patient and other members of the team. When asked to communicate opinion, such a psychiatrist might talk directly about their conclusions without describing the underlying logic, or might refer to biochemical or psychodynamic explanations without considering alternative perspectives and narratives, including that of the patient. Miscommunication is often exaggerated further by existing or assumed deficits in the psychocognitive function of the disordered mind. The concepts of insight and capacity then become central in defensive professional relationships with challenging patients who 'do not know what is best for them'.

The theory in use may not even be compatible with the declared explanatory theory. Often, espoused theories are adopted at early stages of training as an ideological vehicle necessary for legitimation in the eyes of the community of practice. At worst, decision-making might be based on little conscious reasoning beyond rules of thumb, habits, conjectures, values and emotions in combination with selective, uncritical reading of research.

\section{Critical reflection: a challenge to 'theory in use'}

If, instead, critical reflection is integrated into education and facilitated in supervision, peer groups and multidisciplinary meetings, it can become part of the psychiatrist's arsenal for dealing with relationships, case formulations and healthcare provision and can counteract the 'theory in use' model of practice. For Schön (1983), reflectivity is the key to learning through experience and developing 'unrestricted' professionalism. Schon proposed that professionals tacitly use 'reflection-in-action': whenever facing complexity, uncertainty and cognitive conflict they formulate an explanatory theory unique to the case at hand that informs their immediate action. This continues after the event as 'reflection-on-action' during educational and supervisory activities. Theories and actions can be revisited, reformulated and applied in experimental conditions or real practice. The reflective psychiatrist will question their implicit knowledge, engage in a dialogue with colleagues and patients, validate their theories and assumptions and present them to open scrutiny, bringing closer espoused theories and theories in use (Table 1) (Schön 1983; Argyris 1996).

Reflection is a constant, dynamic activity that transcends the single individual and has the potential to reform whole groups or organisations from within. Being a social function, it has a role in criticising group-established hermeneutic and practical frames of reference. I analyse here only the example of the medical model of illness, but there is vast scope for critical reflection in psychiatric practice, where so much more than biomedical work takes place. Stigmatisation of deviance, deprivation of liberty, treatment without consent, tension between the individual and the social good, to name but few, are domains of evaluation, ethics and interpretation, largely influenced by traditional and current dominant discourses. The testing of hypotheses using statistical methods is the most robust approach for bioscientific knowledge in psychiatry (e.g. in the development of pharmacological treatments). On the other hand, qualitative and reflective methods are necessary to critically review and develop mental health law, sociology, psychodynamics and service management

\section{Limitations of reflective psychiatry}

Schön's work, ground-breaking in its time, has been the subject of refreshing critique (Eraut 1994; Ixer 1999) arguing that the critical reflection of everyday practice it evangelised was not evident in the writer himself as he played down the sociocultural context highlighted by others (Boud 1985; Lave 1991). Nevertheless, the need for an alternative to positivism is so strongly felt that reflective practice, although it has not met consensus at either a conceptual or a practical level, might be haphazardly imposed in education and professions, applied by practitioners who have no clear understanding of what it entails, taught 
and appraised by teachers or supervisors who are not themselves reflective.

\section{Lack of validation}

Although theoretically robust, reflective practice has not been extensively validated in real-life applications. There are reasons to doubt its practical merits: reflection is arduous, even unsettling, compared with tacit, habitual modes of practice, and can be met with resistance. Research has raised the question that some students and professionals might have genuine difficulty in reflecting because of their individual cognitive and learning styles, albeit this remains a controversial issue (Kolb 1984; Merrill 2000; Coffield 2004; Paschler 2010).

\section{Lack of time}

The relevance of having time to reflect was compellingly argued in the context of social work (Ixer 1999); I draw parallels with psychiatry, where decisiveness is often necessary in situations that involve the risk of violence or self-harm. It is debatable whether 'reflection-in-action' can be employed so swiftly, or whether well-rehearsed skills are then at play; proper reflection seems to require some detachment and interruption of action not afforded by many real-life situations. Similarly, the vast breadth of the psychiatry syllabus can act as a strong argument against methods that require more time and exploration, albeit it could be counterargued that, in the long-run, reflection is more economic, because it counteracts strategic learning and equips doctors to deal with novel situations that factual knowledge cannot predict.

\section{Need for technical rationality}

Promoting critical reflection should not be equated with denial of the multiplicity of knowledge within psychiatry or construed as an antithesis to objectivity. The impressive advances in therapeutics we have witnessed over the past 30 years have to be credited to the biomedical side of psychiatry and, despite its limitations, it still offers hope of finding more causal links and practical treatments. Denying technical rationality and evidence-based practice is a dogmatism just as perverse as denying the uniqueness of the individual, their narratives and meaning. I stressed that the art in psychiatry lends gravitas to reflective practice, but we should keep in mind that psychiatry is also a branch of biological science that demands a foundation of objective knowledge to grow. Thinking back to Schön's reflective practitioner, patients surely dislike a detached expert who ignores subjective experience and never admits ignorance, but would feel equally disconcerted in the hands of a psychiatrist who has no answers to questions of fact.

\section{Oppression and demoralisation in the name of reflection}

Thinkers have argued that the quintessential function of critical reflection is to lay the grounds for emancipation. The liberation of reflection will require substantial change in the way apprenticeships channel the legitimate participation of juniors. We should be wary and challenge any potential for oppression in the name of reflection. Modern medical education stresses accountability, and stakeholders demand clearly defined and assessed outcomes. Since there is no consensual understanding or technical means of objectively assessing reflection, any attempt to include it in mandated outcomes should be regarded with suspicion (Ixer 1999). Nevertheless, the recording of reflection is already advocated for use in appraisal and it might not be long before unreflective enthusiasts proceed to its inclusion in summative assessment schemes. Both extremes are hazardous: institutional communities can act oppressively either by restricting substantial reflectivity or, conversely, by perverse applications in systems of conformism management.

Hierarchy might equally prevent critical reflection in established professionals. As they find their niche of central participation and expand their responsibilities to include nurturing the development of juniors, it appears that, more confident of their status, they experience less of the cognitive conflict necessary for reflection and self-awareness. A feeling of failure, dissonance or disequilibrium is argued to be essentially positive as material for reflection (Cunningham 2008), but it can have a demoralising by-product of constant self-doubt. It could equally be argued that professionalism requires a balance of restorative and maintenance functions, the identification and reward of the positive rather than constant emphasis on deficits. Striving for continuous improvement is itself a socially prevalent discourse and, as such, can be seen as a product of its time and place, not as an absolute good.

\section{Critical reflection without outlet or end}

Theory claims that the reflective individual is in a better position to identify situational shackles and challenge them accordingly. In most definitions, the value of reflection is seen in consequent praxis, usually implying change. Freire (1971) warned that reflection without outlets for praxis becomes meaningless 'verbalism'. One has to wonder 
whether awareness of intractable situations is any better than ignorance. It is anyway doubtful that total intellectual emancipation is feasible or necessary. In the past, it was identified with 'total' theories with pretence to all the answers - 'metanarratives' that postmodernism warned us not to trust (Lyotard 1984). Any thought, no matter how noble and ambitious in its horizons, is in essence always socially constructed, partial and contextbound. In this sense, reflection can never reach the promise of realisation on an epistemologically or ethically privileged plane. Meta-reflection can thus become an infinite process, a barrier to praxis, without which the profession's existence is meaningless. Reflection can also be a source of excessive anxiety and insecurity when it attempts the impossible feat of encompassing all of the alternative discourses that are continually proliferating in our era of 'supercomplexity' (Barnett 2000).

\section{Conclusions}

Theoretical multiplicity and practical difficulties render critical reflection an imperfect model for psychiatric practice. Nevertheless, it can complement technical rationality as the basis of an epistemology and method of knowledge that enables lifelong development through constructive exploration of new experience in the light of old, independent of authorities or restrictive communities. In parallel, true reflectivity in psychiatry inevitably leads to a pluralism of knowledge, artistry and hermeneutics and a critical consciousness that transcends its topical, individual or social constraints. Approached with humility, it can help the acceptance of our partiality and imperfection and will allow tolerance of uncertainty. Ultimately, it helps psychiatrists to coexist harmoniously with a multivoiced world and to be prepared at any moment to challenge assumptions about their knowledge and the ways they think and act in order to reach their full potential.

\section{References}

Argyris C, Schön D (1996) Organisational Learning II: Theory, Method and Practice. Addison-Wesley.

Atkins S, Murphy K (2003) Reflection: a review of the literature. Journal of Advanced Nursing 18: 118-9.

Barnett R (2000) University knowledge in an age of supercomplexity. Higher Education 40: 409-22.

Boud D, Keogh R, Walker D (1985) Reflection: Turning Experience into Learning. Kogan Page.

Boud D, Walker D (1990) Making the most of experience. Studies in Continuing Education 12: 61-80.

Branch W (2005) Use of critical incident reports in medical education: a perspective. Journal of General Internal Medicine 20: 1063-7.

Brookfield SD (1987) Developing Critical Thinkers. Open University Press.
Coffield F, Moseley D, Hall E, et al (2004) Learning Styles and Pedagogy in Post-16 Learning: A Systematic and Critical Review. Learning and Skills Research Centre.

Cunningham B (2008) Critical incidents in professional life and learning. In Exploring Professionalism (ed B Cunningham): 161-89. Institute of Education.

Dewey J (1933) How We Think: A Restatement of the Relation of Reflective Thinking to the Educative Process. Henry Regnery.

Dilworth RL (1998) Action learning in a nutshell. Performance Improvement Quarterly 11: 28-43.

Engeström $Y$ (2001) Expansive learning at work: toward an activity theoretical reconceptualization. Journal of Education and Work 14: $134-5$.

Eraut M (1994) Developing Professional Knowledge and Competence. Falmer.

Freire P (1971) Pedagogy of the Oppressed (trans M Bergman Ramos). Penguin.

General Medical Council (2006) Good Medical Practice. GMC.

General Medical Council (2009) Tomorrow's Doctors. GMC

Gibbs G (1988) Learning by Doing: A Guide to Teaching and Learning Methods. Further Education Unit.

Grant S, Holmes J, Watson J (1993) Guidelines for psychotherapy training as part of general professional psychiatric training. Psychiatric Bulletin 17: $695-8$

Grant J, Kilminster S, Jolly B, et al (2003) Clinical supervision of SpRs: where does it happen, when does it happen and is it effective? Medical Education 37: 140-8.

Habermas J (1971) Knowledge and Human Interests (trans J Shapiro). Beacon Press.

Hopkins S (1994) What is a Balint group? Journal of the Balint Society 22: $36-7$.

Hoyle E (1974) Professionalism, professionality and control in teaching. London Review of Education 3 (2): 13-30.

Ixer G (1999) There's no such thing as reflection. British Journal of Social Work 29: 513-27.

Jones G (2005) Gatekeepers, Midwives and Fellow Travellers: The Craft and Artistry of the Adult Educator. Mary Ward Centre.

Kilminster SM, Jolly BC (2000) Effective supervision in clinical practice settings: a literature review. Medical Education 34: 827-40.

Kolb DA (1984) Experiential Learning: Experience as the Source of Learning and Development. Prentice Hall.

Korthagen FA (2001) Linking Practice and Theory: The Pedagogy of Realistic Teacher Education. Lawrence Erlbaum Associates.

Launer J (2006) Supervision, Mentoring and Coaching: One-to-One Learning Encounters in Medical Education. Association for the Study of Medical Education.

Lave J, Wenger E (1991) Situated Learning: Legitimate Peripheral Participation. Cambridge University Press.

Lewin K (ed) (1948) Resolving Social Conflicts: Selected Papers on Group Dynamics. Harper \& Row.

Lyotard JF (1984) The Postmodern Condition: A Report on Knowledge. Manchester University Press.

Merrill D (2000) Instructional strategies and learning styles: which takes precedence? In Trends and Issues in Instructional Design and Technology (eds R Reiser, JV Dempsey): 99-106. Prentice Hall.

Mezirow JD (1981) A critical theory of adult learning and education. Adult Education Quarterly 32: 3-24.

Mezirow JD (1997) Transformative learning: theory to practice. New Directions for Adult and Continuing Education 74: 5-12.

Paschler H, McDaniel M, Rohrer D, et al (2010) Learning styles: concepts and evidence. Psychological Science in the Public Interest 9: 105-19.

Popper K (1968) Conjectures and Refutations. Harper and Row.
MCQ answers

$1 b \quad 2 c \quad 3 b \quad 4 d \quad 5 b$ 
Rodgers C (2002) Seeing student learning: teacher change and the role of reflection. Harvard Educational Review 72: 230-53.

Rolfe G, Freshwater D, Jasper M (2001) Critical Reflection for Nursing and the Helping Professions: A User's Guide. Palgrave Macmillan.

Royal College of Psychiatrists (2010a) A Competency Based Curriculum for Specialist Training in Psychiatry (GMC Approved June 2010). Royal College of Psychiatrists.

Royal College of Psychiatrists (2010b) Good Psychiatric Practice: Continuing Professional Development (2nd edn) (College Report CR157). Royal College of Psychiatrists.
Sackett DL (1991) Clinical diagnostic strategies. In Clinical Epidemiology: A Basic Science for Clinical Medicine (2nd edn) (DL Sackett, RB Haynes, P Tugwell, et al): 1-16. Lippincott Williams \& Wilkins.

Schön D (1983) The Reflective Practitioner: How Professionals Think in Action. Temple Smith.

Schön D (1987) Educating the Reflective Practitioner. Jossey-Bass.

Stenhouse L (1975) An Introduction to Curriculum Research and Development. Heinemann.

Tripp D (1993) Critical Incidents in Teaching: Developing Professional Judgement. Routledge.

\section{MCOs}

Select the single best option for each question stem

\section{Reflection:}

a refers to unconscious reactions to therapeutic transference

b can lead to perspective transformation and emancipation

c is a passive process of restructuring an experience based on prior knowledge and future objectives

d requires an established frame of reference

e involves a series of 'trial and error' attempts.

2 Reflection from the learner's perspective:

a reflection is particularly helpful in acquiring factual knowledge

b reflection is more effective when applied to familiar concepts using 'rules of thumb'

c reflection is can be disrupted by hierarchy and lack of concrete experience

d reflection cannot be applied in a group setting e reflection should be constructively applied for 'debriefing' after supervision encounters.

3 Reflection from the teacher's perspective:

a reflection usually disrupts the efficient transmission of facts

b teachers should create environment and opportunities conducive to student reflection and discovery

c good preparation would limit exposure of ignorance and embarrassment

$\mathrm{d}$ reflection can be dangerous as it analyses attitudes and values challenging stigma

e teachers need to be provocative in order to elicit reflective reactions in students.

4 As regards reflective practice in psychiatry:

a it is risky in situations of uncertainty, so is better avoided altogether

b it is impossible 'on your feet' and always requires retrospective work
C it is useful to juniors, but prevents established psychiatrists from transforming systems and organisations from within

d it can help discover discrepancies between espoused and tacit theories of decision-making

e the medical model of illness is usually an invaluable 'theory in use'.

5 Reflective practice is of limited use in psychiatry because:

a positivism and research will eventually provide all the answers

b reflection requires some detachment and interruption of action not afforded by many real-life situations

c it usually indicates the ignorance and weak evidence base of the practitioner

d some individuals are unable to learn through reflection

e it can make practitioners feel omnipotent. 